\title{
Objetos textuales y dispositivos colaborativos: de la etnografía como plataforma pública
}

\author{
Textual Objects and Collaborative Devices: \\ On Ethnography as a Public Platform
}

\author{
Isaac Marrero Guillamón \\ Goldsmiths, University of London \\ i.marrero@gold.ac.uk
}

\section{RESUMEN}

Este artículo traza el inesperado devenir colaborativo acontecido en el transcurso de una investigación etnográfica en Hackney Wick (Londres) en torno al rol del arte en la crítica a la transformación urbana asociada a los Juegos Olímpicos de Londres 2012. El descarrilamiento de lo que debía haber sido un ejercicio clásico de trabajo de campo condujo a una reformulación del ejercicio etnográfico como dispositivo colaborativo orientado a la producción de objetos textuales que a su vez actuaban como foro o plataforma pública. Este proceso se discute aquí como un gesto recursivo (o parasítico) que se apropia, y versiona, prácticas y modos de hacer propios del campo.

Palabras clave: Arte público; Londres; Metodología; Colaboraciones experimentales.

\section{SUMMARY}

This article traces the unexpected becoming-collaborative of an ethnographic project in Hackney Wick (London) which looked at the role of art in the critique to the urban transformations brought about by the 2012 Olympics. The derailment of what should have been a conventional fieldwork exercise led to a reformulation of the ethnographic practice as a collaborative device aimed at the production of textual objects which in turn acted as public forums or platforms. This process is here discussed as a recursive (or parasitic) gesture which appropriates native ways of doing.

Key words: Public Art; London; Methodology; Experimental Collaboration. 
Durante mucho tiempo, en conversaciones informales y confesiones de pasillo, me referí a mi trabajo de campo en Hackney Wick, en el Este de Londres, como un fracaso. Cuando empecé la investigación en 2011, esta antigua zona industrial, aislada del resto de la ciudad por una red de canales y autopistas, era aún un barrio relativamente asequible y poco conocido. La yuxtaposición de pequeñas industrias, solares vacíos, usos informales del espacio público y fábricas reconvertidas (en talleres de artista, unidades de live/work y viviendas tipo loft) le daba al área un aire típicamente post-industrial que contrastaba marcadamente con los barrios residenciales de los alrededores, así como el frenesí constructivo al otro lado del canal, donde tenía lugar el proyecto de reforma urbanística más ambicioso del Londres contemporáneo: la construcción del Parque Olímpico. Hackney Wick se encontraba en una suerte de "tregua urbanística"; las Olimpiadas y la crisis habían desviado la atención y los intereses inmobiliarios a otras zonas y generado un intersticio al amparo del cual había surgido una cierta escena artística, así como múltiples iniciativas de interés en relación a la cuestión que orientaba mi investigación: el rol del arte en la producción de espacios de disenso con respecto a la transformación olímpica. Durante algo más de dos años intenté llevar a cabo una serie de mini-etnografías en torno a proyectos artísticos críticos con el impacto de las olimpiadas en el área. Pero el plan original, basado en ejercicios de observación participante con artistas, se mostró enseguida impracticable.

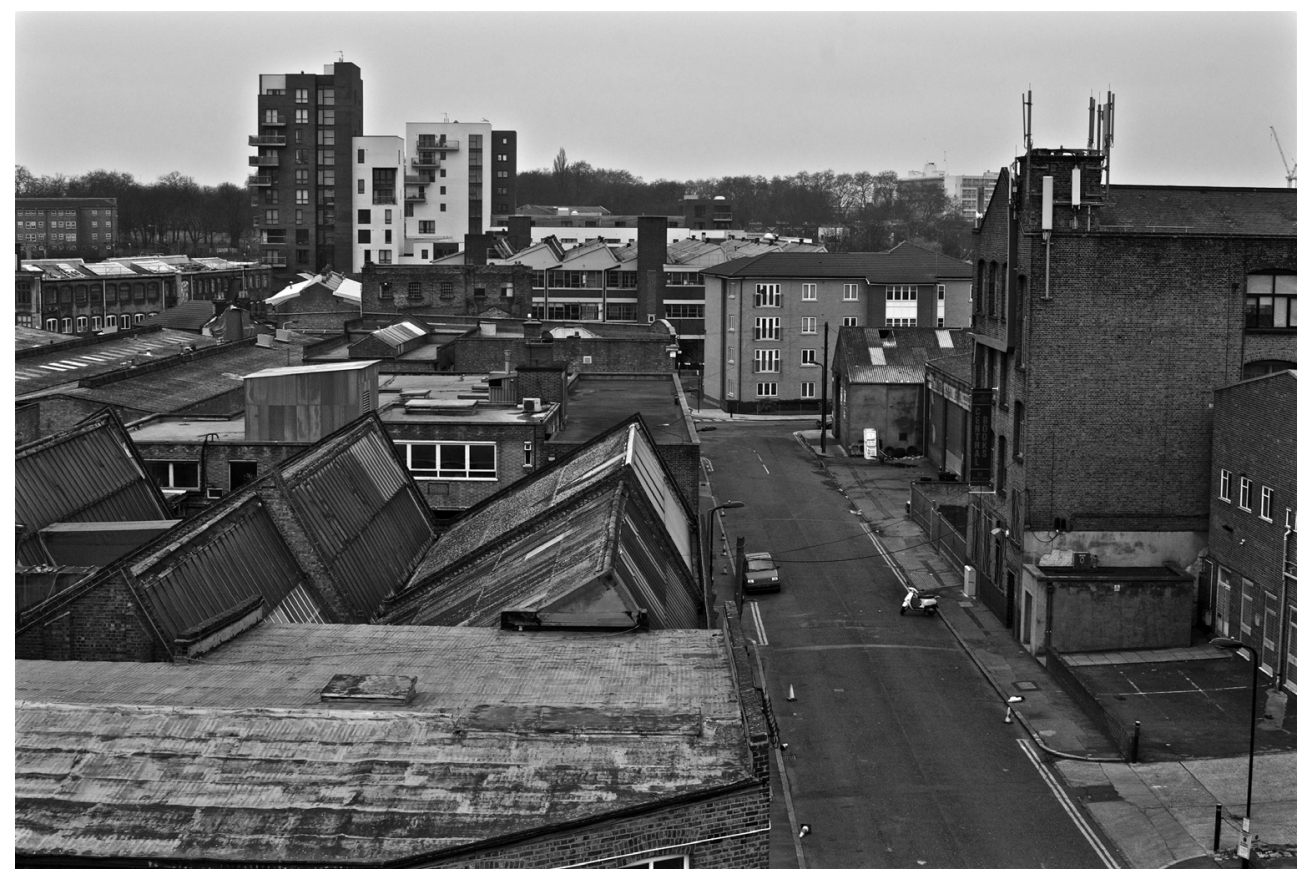

IMAGEN 1.-Vista general de Hackney Wick en 2011. Foto del autor.

Mi primer caso de estudio era la obra Olympic State de Jim Woodall (2011). Se trataba, originalmente, de una performance de dos semanas, durante las que había 
vivido en una caseta de seguridad autoconstruida en la azotea de un antiguo almacén industrial, "vigilando" el Parque Olímpico, por aquél entonces aún en construcción. La obra iba a ser convertida en una instalación para la galería See Studio, un proceso que me interesaba especialmente en relación a la "traducción" de su dimensión política. Apenas unas horas después de comenzar el trabajo de campo, en cuanto nos dimos cuenta de que sería prácticamente imposible completar la reconstrucción de la caseta en el plazo establecido, me había convertido en un asistente a tiempo completo, y con ello perdido la disciplina de las notas de campo. Más aún, Woodall me había invitado - y yo había aceptado- a co-comisariar un evento de veinticuatro horas (24-hr Olympic State) que debía volver a transformar la instalación en una performance y un espacio-tiempo para pensar críticamente sobre las Olimpiadas. De este modo, había acabado co-produciendo el tipo de "objetos de estudio" que había ido a etnografiar. "¿Qué clase de validez puede tener una investigación asî?", me preguntaba mientras esperaba una oportunidad para poder empezar de verdad mi trabajo de campo.

El paso del tiempo, sin embargo, sólo complicó el escenario. Descubrí, por ejemplo, que una artista local, Hilary Powell, estaba editando un libro sobre la respuesta que desde el arte se le había dado a la transformación del Este de Londres en relación a las Olimpiadas, una idea muy similar a la que yo había prometido al Ministerio de Educación Español (cuya beca financiaba mi investigación). Tras colaborar en la organización de un "maratón" de debates públicos que había de alimentar nuestros respectivos proyectos, decidimos unir fuerzas y co-editar un sólo volumen (Powell y Marrero-Guillamón 2012). Así, no sólo se había desintegrado mi primer caso de estudio, sino que apenas transcurridos unos meses había ya renunciado también a "mi" libro.

Los descarrilamientos siguieron sucediéndose con rapidez. A raíz la exposición de Woodall pasé muchas horas en See Studio, llegando a trabar cierta amistad con el galerista, Daren Ellis. Era un espacio muy interesante para mí, en tanto aspiraba a erigirse en la referencia para la reflexión crítica sobre la transformación olímpica del Este de Londres. En cierto momento Ellis me invitó a ser el editor de un periódico de barrio que quería publicar. Aunque la oferta no me interesaba como tal (otra distracción era lo último que necesitaba), fui incapaz de rechazarla, en parte porque pensaba que sería útil como estrategia para acceder a posibles casos de estudio, en parte porque era una buena excusa para pasar más tiempo en See Studio — quizá un espacio clave para esa etnografía que algún día escribiría. Pero editar The Wick se convirtió en un trabajo a tiempo completo durante tres veranos consecutivos, cuya propia mecánica aniquilaba la posibilidad de convertirse en plataforma de lanzamiento de investigaciones etnográficas. Procesos similares ocurrirían con el colectivo de arte y arquitectura public works (hubiera querido etnografiarles y acabamos colaborando en varios proyectos) y con los fotógrafos Giles Price y Chris Dorley-Brown -a los que nunca logré investigar propiamente, pero con los que trabajé en repetidas ocasiones.

En resumen: había querido ser un etnógrafo clásico, un "mero" observador participante, pero había devenido un colaborador y un actor en el campo. Me había imaginado un trabajo de campo basado en algún tipo de distancia con los "objetos" de estudio, y sin embargo, había participado en la producción de muchos de ellos. Había perdido la disciplina en la escritura de notas de campo, y no obstante escribía muy a menudo para los proyectos en los que colaboraba. La narrativa del "fracaso" (que in- 
cluía como ingrediente fundamental el miedo a haberme vuelto nativo) era la única disponible dentro de mi marco de referencia.

No fue hasta que compartí la experiencia que acabo de resumir a algunos colegas (varios de los cuales escriben en estas páginas también) que pude empezar a librarme de este relato y empezar a construir una interpretación alternativa y más constructiva de mi trabajo de campo en relación a la noción de "etnografía colaborativa" (Kelty et al. 2009; Marcus y Holmes 2008; Rappaport 2008). Lo que sigue es, por tanto, un gesto analítico retrospectivo, el resultado de un análisis retroactivo.

\section{MODOS DE HACER}

En un contexto en el que la mayoría de las instituciones culturales de la ciudad, los medios de comunicación de masas, e incluso las universidades mostraron escaso interés en explorar de manera sistemática los aspectos más problemáticos de la transformación Olímpica, esta discusión tuvo lugar en espacios relativamente periféricos, muchos de los cuales estaban vinculados a iniciativas artísticas. El Olympic Artist Forum y la serie Legacy Now, ambos iniciados por SPACE Studios; el Salon de Refuse Olympique organizado por Hilary Powell; o las Friday Sessions de public works son algunas de las iniciativas que desde 2007 generaron foros de diálogo e intercambio de ideas entre artistas y públicos interesados en una visión crítica de los cambios que estaban teniendo lugar en el Este de Londres. Este tipo de espacios constituyeron lo que siguiendo a Meg McLagan y Yates McKee (2012) llamaré "plataformas", es decir, foros o infraestructuras para el encuentro y la mediación entre ciertos grupos o asuntos y un público o audiencia (que, por otro lado, se considera un efecto perfomativo de la propia plataforma, y no una formación preexistente). "Poner en común" o "hacer público" deviene así un gesto constituyente que permite la formación y circulación de ideas, afectos y colectividades.

Estas plataformas eran parte integral de una "infraestructura relacional" que, en forma de préstamos de tiempo, experticia, mano de obra, intercambio de contactos, favores y oportunidades de trabajo, invitaciones recíprocas, exposiciones colectivas, etc. sostenía una serie de prácticas artísticas desarrolladas en condiciones de relativa precariedad, con muy escasos recursos monetarios. Es importante subrayar que estas colaboraciones no tenían como objetivo la co-producción de obra artística, sino el sostenimiento de la propia infraestructura relacional que a su vez hacía posible el desarrollo de la práctica artística. Este tejido relacional en régimen de reciprocidad proveía las condiciones materiales para que estos artistas (re-)distribuyeran su trabajo y su persona - parafraseando a Marilyn Strathern, se podría decir que en lugar de producir proyectos artísticos a partir de personas, se produjeron personas (artistas) a partir de proyectos artísticos (Sansi 2015).

Mi argumento central es que el tipo de etnografía que acabé practicando, orientada a la producción colaborativa de plataformas públicas, no es sino una versión de este "modo de hacer" (Hallam e Ingold 2007) propio del campo. Se trataría así de una estrategia "parasítica" o de un gesto "recursivo" similar a lo que Holmes y Marcus (2008: 82) describen como la "deferencia hacia los modos de saber de los sujetos [con los que colaboramos]". No obstante, a diferencia de los contextos de expertos en los que 
estos autores han desarrollado su propuesta, en mi caso el aspecto central de la relación colaborativa no fue tanto la co-producción de conocimiento como tal, sino la adopción de un modo "nativo" de organización en torno a la producción de los foros o plataformas descritas anteriormente. En otras palabras, el proceso etnográfico devino un dispositivo colaborativo orientado a performar lo público, a generar espacios de encuentro, de debate, de discusión —un modo de hacer, más que un modo de "saber". A continuación trataré de desarrollar esta idea a partir de dos ejemplos sacados del trabajo de campo, que muestran cómo la co-producción de "objetos textuales" contribuyó a la generación de plataformas y como este proceso reformuló mi entendimiento de la práctica de investigación etnográfica.

\section{TEXTOS QUE SON ALGO MÁS QUE TEXTOS}

Hilary Powell y yo decidimos colaborar en la co-edición de The Art of Dissent después de haber co-organizado el "maratón" de debates públicos mencionado más arriba. La producción del libro fue un proceso largo y complicado, que implicó entre otras cosas compilar más de sesenta trabajos, recaudar fondos, e involucrarnos en el diseño, la producción y la distribución. Durante la mayor parte de los diez meses que duró el proyecto, yo concebí el libro como un objeto discursivo, cuyo objetivo era proponer ciertas ideas, conexiones y debates. Una vez acabado y puesto a la venta - pensaba - podíamos darlo por concluido. Para Powell, sin embargo, estaba claro que había que generar un programa de eventos para "activarlo" — que la publicación, en otras palabras, no era sino el comienzo de la vida social del proyecto. Así, durante Junio y Julio de 2012, con la excusa de presentar el libro, organizamos una serie de actividades (debates, lecturas, proyecciones) en las que invitábamos a nuestros colaboradores (y a otros) a presentar su trabajo.

A posteriori, es obvio que el libro estaba reproduciendo el tipo de "plataforma" de la que que había surgido. Los individuos, grupos, instituciones y espacios que constituían la "infraestructura relacional" del proyecto y el origen de una parte importante de sus contenidos se convirtió rápidamente en su primer público —un público activo, no espectador, que se lo apropió como foro y escenario. La asociación pareció funcionar: los artistas y autores que participaban en estos eventos conectaban con nuevos públicos (distribuyendo así su trabajo y su persona), mientras que nosotros nos beneficiábamos de la vida social del libro en tanto espacio de referencia para la discusión crítica de la transformación olímpica (así como de las ventas asociadas a esto, claro está). De este modo, el espacio discursivo en el que yo había imaginado ciertas conexiones e ideas fue reemplazado por el rico e impredecible espacio de relación social performado en estos eventos públicos. En este proceso, mi investigación etnográfica abandonaba la clásica puesta en escena basada en el encuentro con la alteridad (Marcus 2010) y su posterior captura en forma de texto, y se emplazaba, por el contrario, a una lógica performativa y colaborativa en la que investigación deviene, en sí misma, una plataforma pública.

Un segundo ejemplo ayudará a profundizar en esta reimaginación del proceso etnográfico. Como ya mencioné, entre 2011 y 2013 fui el editor del periódico de barrio The Wick. Se trataba en realidad de una publicación anual, sin apenas "noticias", 
compuesto más bien de artículos de opinión en torno a temas de historia, cultura y urbanismo de relevancia para el área y de una muestra de trabajos de artistas locales. Mas el hecho de que The Wick tuviera forma de periódico no es trivial; de hecho su "vida social" sólo se puede entender en función de ésta. No fue hasta que las 3.000 copias del primer número empezaron a circular durante Hackney WickED, un festival de "puertas abiertas" en el área, que la especificidad del medio impreso me sacudió. Los periódicos ocupaban el espacio público; no en un sentido discursivo, sino material: circulaban visiblemente bajo el brazo, eran leídos u ojeados, desmantelados, utilizados para sentarse en el suelo o cubrirse de la lluvia, llevados al metro... Cuando dos años después encaramos la producción del tercer número, esta vez con presupuesto y una reputación que nos precedía, la idea de usar el periódico como plataforma o foro de debate era ya mi objetivo principal como editor.

$\mathrm{Si}$, como argumentaba en el editorial, Hackney Wick era un importante experimento en la producción informal de espacio urbano, un "prototipo de ciudad temporal hecha desde abajo", la cuestión era presentar estas experiencias como un posible modelo alternativo de desarrollo urbano en el nuevo contexto post-Olímpico, post-tregua urbanística. Los artículos que incluimos iban más allá de una crítica al predominio de los intereses privados en la reconfiguración del barrio; el énfasis estaba en valorizar experiencias locales de auto-construcción y gestión colectiva de espacios y estudiar las condiciones para su posible extensión. Además de esta labor de valorización/imaginación de otro futuro posible, el periódico incluía también un "suplemento" de la socióloga Fran Weber-Newth y el fotógrafo Chris Dorley-Brown en el que se interrogaba el pasado industrial y laboral del barrio a partir de historias de vida oral y materiales del archivo fotográfico.

El periódico actuaba así, a partir de su materialidad y puesta en circulación, como un foro para repensar el pasado, presente y futuro del barrio. De hecho, buscando "amplificar" el debate que proponíamos, imprimimos una serie de posters con imágenes de fábricas y trabajadores ya desaparecidos y torres de vivienda pública siendo demolidas (extraídas del suplemento) y las pegamos en varios lugares estratégicos del área. Además de una intervención literal en la imagen pública del área en un momento crucial, destinada a introducir una medida de la violencia del cambio que estaba teniendo lugar, algunas de estas imágenes devinieron, inesperadamente, en microespacios de debate - acogieron, en su superficie, una serie de "conversaciones en graffiti”; un cruce de elogios y acusaciones en torno a la gentrificación.

Tanto The Art of Dissent como The Wick son ejemplos de "objetos textuales", es decir, textos que son más que textos. Se trata, en primer lugar, de espacios de colaboración estructurados en torno a su producción material (y no su contenido). Más aún, cabría argumentar que su interés desde el punto de vista de las "colaboraciones experimentales" no radica tanto en sí mismos, como objetos terminados, sino en el hecho de que a partir de su especificidad material devinieron "plataformas" públicas. Estos objetos textuales serían, al mismo tiempo, espacios de acogida y de producción de relaciones sociales $-\mathrm{y}$ en este sentido, no pueden considerarse el resultado del trabajo de campo, sino una instancia de este último. Se invierte, de este modo, la relación jerárquica entre texto y trabajo de campo y se abre la posibilidad de pensar en la etnografía como una forma de construcción de espacios públicos. 

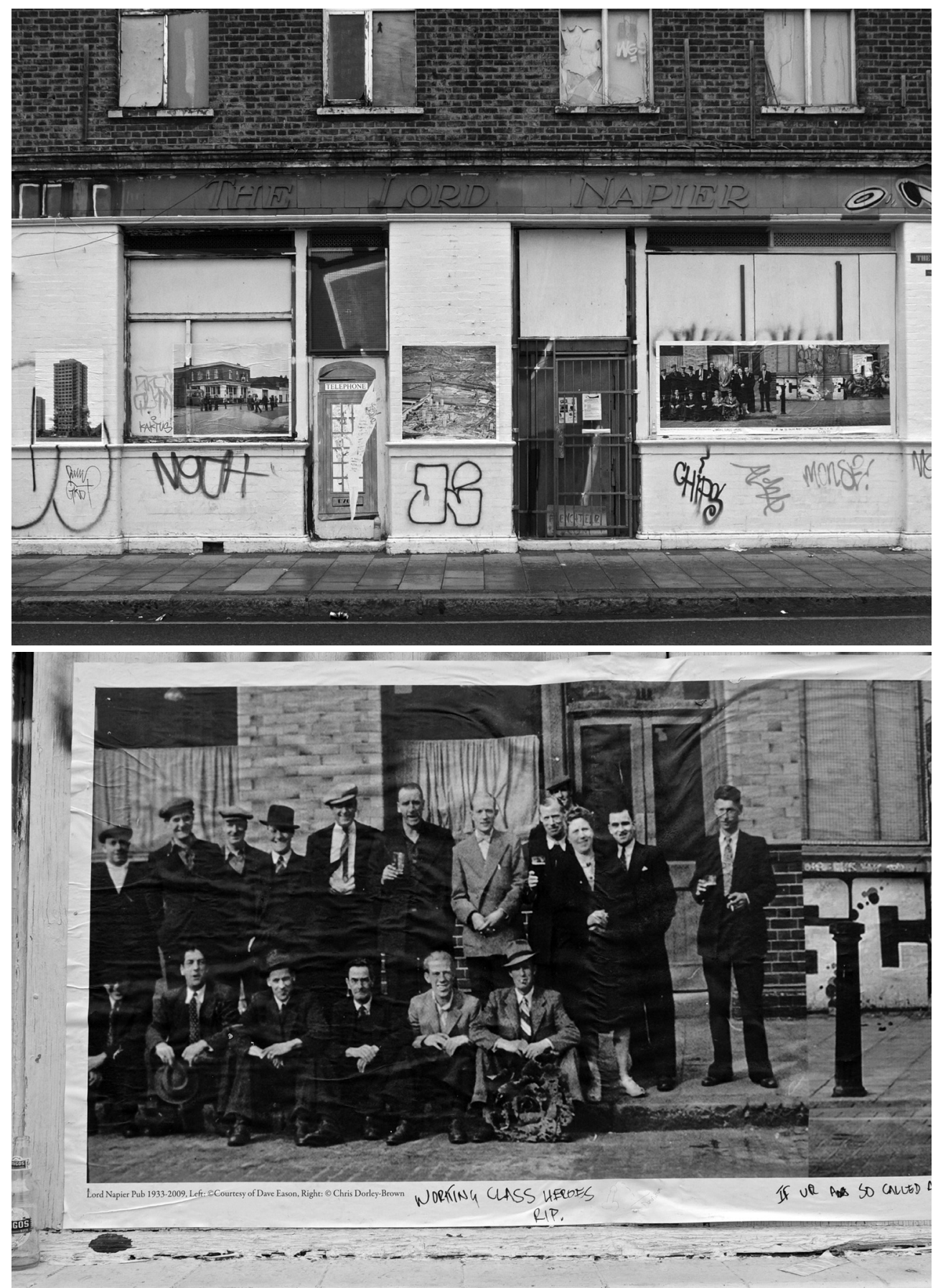

IMÁGENES 2 y 3.-Posters extraídos del suplemento de The Wick y detalle del graffiti "Descansen en paz, héroes de la clase obrera". Fotos del autor. 


\section{AGRADECIMIENTOS}

La investigación de la que surge este texto fue financiada por el Programa de Ayudas de Movilidad Posdoctoral en Centros Extranjeros del Ministerio de Educación Español. Agradezco a Adolfo y Tomás su labor como editores y compañeros en el devenir colaborativo. El argumento que aquí propongo surgió en diálogo con ellos.

\section{BIBLIOGRAFÍA CITADA}

Hallam, Elizabeth y Tim Ingold (eds.). 2007. Creativity and Cultural Improvisation. Oxford: Berg.

Holmes, Douglas R. y George E. Marcus. 2008. "Collaboration Today and the Re-Imagination of the Classic Scene of Fieldwork Encounter». Collaborative Anthropologies 1(1): 81-101. doi: 10.1353/ cla.0.0003.

Kelty, Christopher et al. 2009. "Collaboration, Coordination, and Composition: Fieldwork after the Internet", en James D. Faubion y George E. Marcus (eds.), Fieldwork Is Not What It Used to Be: Learning Anthropology's Method in a Time of Transition: 184-206. Ithaca y Londres: Cornell University Press.

Marcus, George. 2010. "Contemporary Fieldwork Aesthetics in Art and Anthropology: Experiments in Collaboration and Intervention". Visual Anthropology 23(4): 263-77. doi: 10.1080/08949468.2010.484988.

McLagan, Meg y Yates McKee (eds.) 2012. Sensible Politics: The Visual Culture of Nongovernmental Activism. Nueva York; Cambridge, MA: Zone Books - MIT Press.

Powell, Hilary e Isaac Marrero-Guillamón. 2012. The Art of Dissent: Adventures in London's Olympic State. Londres: Marshgate Press.

Rappaport, Joanne. 2008. "Beyond Participant Observation: Collaborative Ethnography as Theoretical Innovation". Collaborative Anthropologies 1 (1): 1-31. doi:10.1353/cla.0.0014.

Sansi, Roger. 2015. Art, Anthropology and the Gift. Londres y Nueva York: Bloombury. 